\title{
GÊNERO E DIVERSIDADE SEXUAL NA BASE NACIONAL COMUM CURRICULAR: descritores ausentes que tornam abjetos os corpos transgressores da norma
}

\author{
Anderson Pereira Evangelista ${ }^{1}$ \\ Rafael Marques Gonçalves ${ }^{2}$
}

\begin{abstract}
RESUMO
O ensaio teórico-reflexivo aqui empreendido busca nos levar a compreensão em termos conjunturais dos movimentos e força-tarefa que resultou no apagamento dos descritores gênero e diversidade sexual na Base Nacional Comum Curricular (BNCC). Partindo do pressuposto de que o currículo é uma seleção intencional de conhecimentos; nos deteremos sobre os interesses e grupos que os advogam, ao tencionar no processo de construção da Base, e com isso, atingir seu objetivo de censurar aquilo que consideram uma ameaça. A reflexão percorre um caminho militante, e é tecida sob o foco de resistência, sendo este o chamamento nas considerações.
\end{abstract}

Palavras-chave: Currículo. Gênero e Diversidade. LGBT.

\section{GENDER AND SEXUAL DIVERSITY IN THE COMMON NATIONAL CURRICULAR BASIS: absent descriptors that make abject bodies violating society's unspoken rules}

\begin{abstract}
This theoretical-reflective essay seeks to contribute to the understanding, in conjunctural terms, of the movements and task forces that resulted in the erasure of the descriptors gender and sexual diversity in the Common National Curricular Basis (known as BNCC in Brazil). Assuming that the curriculum is an intentional selection of different types of knowledge, the essay dwells on the interests and groups that advocate them as they impose themselves in the process of constructing the BNCC, and thus achieve their objective of censoring what they consider a threat. The reflection follows a militant path, and is conducted under the focus of resistance, which is its main call.
\end{abstract}

Keywords: Curriculum. Gender and Diversity. LGBT.

\footnotetext{
1 Licenciado em Educação Física e Mestrando em Educação pela Universidade Federal do Acre (Ufac), Rio Branco, Acre - Brasil. Bolsista CAPES. Orcid iD: http://orcid.org/0000-00030436-4357. E-mail: andersonevangelistaczs@gmail.com

2 Doutor em Educação pela Universidade do Estado do Rio de Janeiro (ProPEd/UERJ). Professor Adjunto e Docente Permanente no Programa de Pós-Graduação em Educação da Universidade Federal do Acre (Ufac), Rio Branco, Acre - Brasil. Orcid iD: http://orcid.org/0000-0002-9038-1542. E-mail: rafamg02@gmail.com
} 


\section{GÉNERO Y DIVERSIDAD SEXUAL EN LA BASE CURRICULAR NACIONAL COMÚN: ausentes descriptores que hacen que los cuerpos que violan la norma sean abyectos}

\section{RESUMEN}

El ensayo teórico-reflexivo realizado aquí busca llevarnos a la comprensión en términos de los movimientos y la fuerza de trabajo que resultó en la eliminación de los descriptores género y diversidad sexual en la Base Curricular Común Nacional (BNCC). Asumiendo que el plan de estudios es una selección intencional de conocimiento; nos detendremos en los intereses y grupos que los defienden, cuando tengan la intención en el proceso de construcción de la Base, y con eso, logremos su objetivo de censurar lo que consideran una amenaza. La reflexión sigue un camino militante, y se teje bajo el foco de la resistencia, que es la llamada en las consideraciones.

Palabras clave: Currículum. Género y Diversidad. LGBT.

\section{INTRODUÇÃO}

"Pai afasta de mim este cálice (cale-se) de vinho tinto de sangue".

(Cálice- Chico Buarque -1973)

A voz é dada ao invertido. Este ensaio teórico é o lugar de fala conferido a um "não recomendado à sociedade". Não recomendado por se reconhecer um homem-gay- cisgênero que se tangencia da heteronormatividade. Assim sendo e estando no mundo, é para expressiva parte da sociedade um corpo pervertido, vil, ligeiramente aproximado de um abjeto. Mas em uma perspectiva de protesto e resistência "[...] o lixo vai falar, e numa boa" (GONZALEZ, 1984, p. 225). Tecido sob um olhar crítico, nos esquivamos de uma compreensão ingênua do objeto, e assumimos um posicionamento militante frente a temática aqui discutida; pois esta a nós diz respeito, para além da perspectiva profissional, é sobre nossas vidas.

A inquietação que move o presente estudo parte das discussões em torno do profícuo campo de pesquisa que é o Currículo. Discussões estas oportunizadas dentro da disciplina de Tópicos Especiais em Educação do Programa de Pós-Graduação em Educação da Universidade Federal do Acre. O fio condutor da reflexão aqui empreendida busca nos levar a 
compreensão em termos conjunturais dos movimentos e força-tarefa que resultou no apagamento dos descritores gênero e diversidade sexual na Base Nacional Comum Curricular (BNCC).

De acordo com o site oficial da Base3, o documento/referência estabelece conhecimentos, habilidades e competências que devem ser desenvolvidos no âmbito da Educação Básica. Partindo do pressuposto de que o currículo é uma seleção intencional de conhecimentos; nos deteremos sobre os interesses e grupos que os advogam, ao tencionar no processo de construção da Base, e com isso, atingir seu objetivo central de censurar aquilo que consideram uma ameaça, mesmo que isto silencie, condene e mate corpos transgressores da norma (heterossexual).

Preliminarmente, voltaremos ao alvorecer de dias "à Direita" que se apresenta nebuloso em termos globais. Os dias marcados pelo ódio e intolerância (TIBURI, 2016) vão se prologando, e vidas humanas importam cada vez menos. Os processos imigratórios de populações em fuga de guerras civis, como a que ocorre na Síria, são sufocados por Nações-Forte que fecham as portas, e defendem veementemente a política antiimigração; negando refúgio e negligenciado a responsabilidade para com os direitos humanos. A ascensão dos partidos de extrema direita ao poder trouxe à tona o famigerado Brexit no Reino Unido, protagonizando o rasgar do tecido social daquela nação. Em 2016 os Estados Unidos elegem o presidente Donald Trump (Partido Republicano), com uma maneira de governar que se espelha nos ideais ultraconservadores e fundamento pragmaticamente neoliberal (ALMEIDA, 2019).

O espiral que se forma em torno da Nova Direita, tem movimento originário nos países do Norte, e vai repercutir de maneira significativa nos países do Sul. É quando chega ao Brasil, que em 2018 elege Jair Messias Bolsonaro à época do PSL (Partido Social Liberal) como novo presidente. Saudosista da Ditadura Civil-militar (1964-1985), o chefe do executivo flerta

3 Disponível em: http://basenacionalcomum.mec.gov.br/. Acesso em: 22 de jun. de 2019. 
explicitamente com as ideias basilares daquele que fora o regime autoritário que calou muitas vozes com sentenças de morte.

A expressão da face nazifascista se mostra fiel aos seus fundamentos, que outrora fora tímida, mas hoje orgulha-se de ser nociva. É seguindo nesta perspectiva que iremos refletir teoricamente o porquê que os descritores gênero e diversidade sexual foram silenciados na BNCC.

É importante frisarmos que isto não é um processo de determinado momento histórico, advém do perene conflito entre conservadores e progressistas no campo da política educacional, de maneira mais específica, dos embates por hegemonia ${ }^{4}$ na arena do currículo.

\section{A ALIANÇA CONSERVAdora QUe FORJA "CIDADÃos DE BEM", (DES) AUTORIZA VOZES E RELATIVIZA VIOLÊNCIAS}

"A tua piscina tá cheia de ratos Tuas ideias não correspondem aos fatos

O tempo não para". (O tempo não para - Cazuza -1988)

Para conceituarmos a aliança conservadora da qual iremos falar neste ponto, tomamos como base o estudo de Michael Apple. Analisando o processo de "viragem para a direita" ou "restauração conservadora" verificado na educação americana, o autor destaca que a aliança a qual nos referimos é formada por quatro grandes grupos que influenciam a política educacional, a conhecer: "neoliberais, neoconservadores, populistas autoritários e uma fração particular de uma nova classe média em ascensão" (APPLE, 2002).

Os advogados do neoliberalismo e o mais forte grupo dentro da aliança discursam pela iniciativa privada em detrimento do Estado provedor e regulador de políticas públicas sociais. Os neoconservadores, os quais

\footnotetext{
4 O conceito de hegemonia a qual fazemos referência foi cunhado pelo filósofo marxista António Gramsci (1891-1937). Ao analisar o processo de desenvolvimento capitalista no contexto italiano o autor descrevia o movimento no campo da disputa por hegemonia, onde determinado grupo social buscava assumir a direção política, econômica e cultural sobre os demais grupos (SCHLESENER, 2016).
} 
Apple denomina teia ideológica, fazem "apologia a um "regresso" ao passado", tem "receio pelo outro", com vistas as virtudes tradicionais (2002, p. 65). Ainda de acordo com o autor:

Os populistas autoritários da "nova direita" baseiam suas posições na educação, em particular, e na política social, em geral, através de visões particulares fundamentadas na autoridade bíblica, tais como, "a moral cristã", o devido papel dos gêneros masculino e feminino e da família (APPLE, 2002, p. 70).

Por último, mas não menos importante está a Nova classe média profissional, que segundo Apple (2002, p. 73) não segue ortodoxamente determinada posição ideológica, mostrando-se mais liberal no aspecto político. Mas o autor adverte que este grupo é o detentor das destrezas técnicas que executam o plano de modernização conservadora. Enveredamos por esta análise de Apple, para compreendermos a onda conservadora que assola o Brasil e suas respectivas raízes ideológicas; colocando em relevo seu epicentro.

No Brasil essa aliança historicamente presente nas arenas discursivas, deliberativas e decisórias determina pautas diretamente implicadas na vida da população trabalhadora que vive nas periferias, daqueles que fogem à regra, que não é dos seus, é o outro. Isso tudo porque a onda conservadora advinda do setorial religioso sob um espectro de atuação tem "pelos menos quatro linhas de forças sociais: economicamente liberal, moralmente reguladora, securitariamente punitiva e socialmente intolerante" (ALMEIDA, 2019, p. 185-186).

Dentro do contexto brasileiro seremos mais enfáticos ao analisar a forma como essa aliança age, compreendendo a gênese dos grupos que a compõe e suas crenças fundamentalistas. Engrenando em um movimento contrário ao acima realizado, analisemos inicialmente a Classe Média do nosso país. Ao ser colocada no espelho mostra sua característica fundante e enraizada no passado, como aponta Souza (2018, p.55):

A classe média brasileira herda o abuso e o sadismo de seus avós, e um dos motivos para isso é que nossa inteligência cooptada e 
colonizada nem sequer percebe a escravidão como a nossa semente social mais importante. A balela do patrimonialismo, e da corrupção como se fosse atributo apenas do Estado e da política, assume o lugar principal e subordina, relega ao esquecimento e torna supérflua essa herança maior. [...] Nossa classe média não apenas explora economicamente as classes abaixo dela, ela humilha covardemente os mais frágeis, os esquecidos e abandonados tanto por ela, classe média, quanto pela "elite do atraso".

Os ideais escravocratas sob os quais se ergueu nossa sociedade são ainda mais perversos do ponto de vista operacional. Eles produzem populistas autoritários e neoconservadores, declaradamente homofóbicos, misóginos e imbuídos de concepções de mundo ancoradas na religião. $E$, diga-se de passagem, evangélica. É o caso do Presidente Jair Bolsonaro5, fortalecido dentro de um ultra projeto conservador, e eleito em 2018, para o mandato (2019-2022).

Como um nítido populista autoritário, propalou em seus discursos uma nova abordagem no modo de fazer política, quando já fora deputado federal pelo Estado do Rio de Janeiro por consecutivos 7 mandatos (19912018). Em uma fala que antecede sua eleição, Bolsonaro no documentário Democracia em Vertigem (2019) da aclamada cineasta Petra Costa dizia: "Eu estou cada dia mais vivo perante a opinião pública", e de fato estava, pois alcançou expressivos $55,13 \%$ dos votos válidos em segundo turno, tornando-se chefe do executivo.

O discípulo de Olavo de Carvalho' trazia como principais bandeiras: a) o antipetismo (RIBEIRO, 2019; LIMA, 2019), combustível para o golpe de Estado, nas palavras do ex-senador Romero Jucá (MDB-RR) "um acordo nacional com o supremo com tudo"7, conduzido contra a Presidenta Dilma Rousseff (PT) em agosto de 2016, b) a demonização ao que eles denominam

\footnotetext{
5 Jair Messias Bolsonaro (Sem Partido) é capitão reformado do Exército Brasileiro, eleito Presidente do Brasil em 2018 pela Coligação "Brasil acima de tudo, Deus acima de todos" (PSL/PRTB), para mandato que vai de 2019 a 2022.

6 Olavo Luiz Pimentel de Carvalho é um ensaísta e pensador brasileiro, sendo considerado também um influenciador digital e ideólogo, e tendo atuado no passado como jornalista e astrólogo. Autoproclamado filósofo, é um representante do conservadorismo no Brasil.

7 Disponível em: http://gl.globo.com/politica/noticia/2016/05/leia-os-trechos-dos-dialogosentre-romero-juca-e-sergio-machado.html. Acesso em: set. 2019.
} 
de "marxismo cultural", contrapondo-se as ideias emancipatórias de António Gramsci (MIGUEL, 2019). E c) o ponto mais duro de sua política harmonizada pelo ódio, a LGBTfobia8, que se naturaliza cotidianamente justificada pela defesa da família. Esta última entendida no sentido mais estrito e religioso do termo, enquanto instituição heteronormativa, cristã e indissociável independente de quaisquer motivos que sejam (BULGARELLI, 2019).

A defesa da família que é sintetizada na hierarquia marido o "cabeça" e a mulher "submissa, bela, recatada e do lar", toma materialidade neste governo através do Ministério da Mulher, da Família e dos Direitos Humanos, dirigido pela advogada e pastora evangélica Damares Alves. Esta mesma família a qual nos referimos é a que forja em seu seio os ditos "cidadãos de bem". Aqueles que são os defensores da moral, dos costumes tradicionais, com o forte apreço pelos anos de chumbo", que foi para Bolsonaro a revolução.

Os "cidadãos de bem" foram integrando um verdadeiro exército em torno do "mito", assim chamado Bolsonaro por eles. As redes sociais especificamente o WhatsApp - projetam Bolsonaro, que foi conquistando via frases prontas e desmoralizações recorrentes, os eleitores que o fizeram presidente. A vitória da extrema direita no Brasil foi sendo construída aos poucos. De acordo com Silveira (2019, p. 36):

Ao término das jornadas de junho de 2013, grupos e coletivos da direita passaram a ser financiados nas redes sociais pelos empresários e forças políticas neoliberais que perceberam o poder das redes. Dinheiro limpo e dinheiro sujo, tal como foi descoberto com os pagamentos da JBS ao MBL, permitiram a construção de inúmeros pontos de combate neoliberal que iam da centro direita a extrema direita nas redes digitais. Plataformas como Facebook e Youtube

\footnotetext{
${ }^{8}$ A LGBTfobia pode ser definida como a rejeição, o medo, o preconceito, a discriminação, a aversão ou o ódio, de conteúdo individual ou coletivo, contra aquelas (es) que, supostamente, sentem desejo ou têm práticas sexuais com indivíduos do mesmo sexo biológico. Atuando, ainda, como uma forma específica de sexismo, o comportamento LGBTfóbico, hostiliza e rejeita todas (os) aquelas (es) que não se conformam com o papel de gênero predeterminado socioculturalmente para o seu sexo biológico. Trata-se, portanto, de uma construção social que consiste numa permanente promoção de apenas uma forma de sexualidade (heterossexual) e de uma única forma de identidade de gênero (Cisgênero) em detrimento de outras formas de desejo, como o desejo homoafetivo e de outras construções identitárias de gênero, como a trans (BRASIL, 2016).
}

9 Refere-se ao Período da Ditadura Militar no Brasil (1964-1985). 
receberam muitos recursos para que esses coletivos e líderes de opinião conquistassem milhões de seguidores. O discurso combinava o ódio ao PT, caracterizado como representação da corrupção e da defesa "dos vagabundos que vivem do bolsa família", o ataque aos programas sociais, a defesa da redução máxima do Estado, o enaltecimento de valores como a bandeira brasileira, as Forças Armadas, a família cristã e o ataque ao feminismo.

O mais desalentador ainda é perceber que a "avalanche bolsonarista" instalou via processo democrático vozes odiosas dos ditos "cidadãos de bem" no poder legislativo. A polêmica Bancada Parlamentar Evangélica fora oxigenada consideravelmente. De acordo com Lima (2019) houve nas últimas eleições a saída de conhecidos nomes da política, e "todas essas vacâncias parecem ter sido ocupadas pelo PSL, o quadro que mais cresceu. De assombrosos 1 parlamentar, em 2014, para 52, em 2018, tornou-se a segunda maior legenda do Congresso nos próximos quatro anos" (p. 664). Justamente, o partido que fazia parte o presidente.

Inaugura-se, portanto, uma ditadura simbólica, travestida de preceitos democráticos quando vozes são (des) autorizadas e o medo faz calar simplesmente. É o que ocorreu com o ex-deputado federal Jean Wyllys (Partido do Socialismo e Liberdade - PSOL/RJ), declaradamente gay e ativista da causa LGBT; foi reeleito em 2018 para Câmara dos Deputados Federais. Com a chegada de seu inimigo ideológico ao poder, passou a sofrer inúmeras ameaças de morte, e decide não assumir o cargo deixando - Brasil (durante o período da Ditadura 1964-1985, muitos que eram contrários ao regime, para preservar suas vidas buscaram exílio em outros países).

Imaginemos as milhares de vidas homossexuais, bissexuais e transexuais, em tempos que os "cidadãos de bem" se veem encorajados e representados nas falas do presidente, e de seus correligionários; como declarou a Ministra Damares Alves: "É uma nova Era no Brasil: menino veste azul e menina veste rosa"10.

10 Disponível em https://oglobo.globo.com/sociedade/menino-veste-azul-menina-veste-rosadiz-damares-alves-em-video-23343024. Acesso em: set. 2019. 
Os seres "sodomitas" assim denominados no Brasil Império (GREEN e POLITO, 2004) mesmo com leis que no papel thes garante o direito à vida são mortos todos os dias. De acordo com o Relatório 2018 do Grupo Gay da Bahia (GGB): "A cada 20 horas um LGBT é barbaramente assassinado ou se suicida vítima da LGBTfobia, o que confirma o Brasil como campeão mundial de crimes contra as minorias sexuais" (2018, p. 01). Os dados do relatório revelam ainda que $420 \mathrm{LGBT}+$ morreram de forma violenta em 2018. Destes $76 \%$ foram homicídios e $24 \%$ suicídios.

A realidade é amedrontadora e nos cerca de medo, uma vez que as violências são relativizadas por aqueles que colocaram o ódio fora do armário, respaldados em uma figura pública que antes era piada e se tornou presidente. Valim e Fernandes (2019, p. 402) são categóricos ao avaliar que:

\begin{abstract}
Um dos aspectos que possibilitou esse deslocamento de um lugar de jocosidade para uma posição presidencial foi a apropriação do discurso sexista e LGBTfóbico, tornando as mulheres (especialmente as feministas) e as pessoas LGBTs os principais "bodes expiatórios" de uma suposta crise dos valores dos "cidadãos de bem" e da "família brasileira".
\end{abstract}

A relativização das violências contra a população LGBT se mostrou de forma explícita durante a campanha eleitoral para governador do Rio de Janeiro. Em um dos comícios do governador eleito Wilson Witzel (Partido Social Cristão - PSC/RJ), dois candidatos a deputado, um federal e outro estadual pelo PSL, quebraram a placa que homenageava a vereadora Marielle Franco (PSOL-RJ), brutalmente assassina na noite do dia 14 de março de 2018, junto com seu motorista ${ }^{11}$. Marielle era negra, lésbica, feminista e defensora dos direitos humanos, para os algozes que quebraram sua placa uma "esquerdopata" que não merece ser lembrada.

Um crime que guarda no bojo de sua investigação um enorme sinal de interrogação. Os dias vão se passando, e os culpados pela morte tanto de Marielle Franco quanto de seu motorista não são encontrados. A injustiça se

11 Disponível em: https://politica.estadao.com.br/noticias/eleicoes,candidatos-do-psldestroem-placa-com-homenagem-a-marielle-franco,70002531740. Acesso em: set. 2019.

Revista Exitus, Santarém/PA, Vol. 10, p. 01-26, e020065, 2020. 
impera neste e em tantos outros casos, que são arquitetados ao que tudo indica nos porões milicianos.

A forte aversão a quem não congrega e compartilha das mesmas ideias do grupo que se encontra no poder parece não encontrar limite, o que nos faz corroborar com Valim e Fernandes (2019, p. 403) quando colocam que "no bolsonarismo os "inimigos da pátria" são predominantemente pessoas de esquerda e as chamadas minorias sociais feministas, indígenas, militantes negras e negros, ativistas LGBT etc.", que em resumo devem ser eliminados.

Desenhamos este panorama para que inicialmente pudéssemos compreender de onde parte o silenciamento dos descritores gênero e diversidade sexual na BNCC. Partindo de um uma base ideológica que se ramifica e opera nos mais diversos setores, a censura dos termos que reconhecem as nossas diversidades, transgredindo com o binarismo, se faz nas diferentes arenas. Ela nos rouba a dignidade, e nos torna o mal a ser combatido todos os dias. Como veremos a seguir.

\section{GÊNERO E DIVERSIDADE SEXUAL: da censura cotidiana à institucionalizada na BNCC}

Por isso cuidado, meu bem Há perigo na esquina Eles venceram e o sinal está fechado para nós que somos jovens. (Como nossos pais - Belchior - 1976).

A LGBTfobia nos cerca cotidianamente. "Pode-se dizer, sem medo de errar, que sofrer algum tipo de insinuação, ofensa verbal ou de ameaça de agressão física faz parte da experiência social de gays, lésbicas, bissexuais, travestis e transexuais no Brasil" (SIMÕES e FACCHINI, 2009, p.26). Isso ocorre porque nos imaginários daqueles que a todo custo buscam conduzir os parâmetros das relações sociais, o:

[...] corpo deve ser educado para produzir e reproduzir o modelo normativo vigente. Xs que desviarem da norma, serão alvo de permanente proibição sendo penalizados por sanções sociais 
concernentes. Dessa maneira, é necessário compreender que as identidades sexuais são concebidas pelas relações de poder de uma sociedade, constituída historicamente, por meio de discursos reguladores sobre o sexo (RIOS, DIAS e BRAZÃO, 2019, p. 786).

Os autores afirmam ainda que:

Desde o nascimento, somos educadxs no sentido de atender a um conjunto de expectativas sociais acerca do que é ser homem ou ser mulher, concernentes aos papéis que devemos executar, sendo estes demarcados e atribuídos através das relações de gênero e hierarquias sexuais fundamentadas apenas em questões biológicas (RIOS, DIAS e BRAZÃO, 2019, p. 786-787).

Na sociedade nocivamente machista como a brasileira, a modulação dos corpos dentro de padrões estanques, e discursivamente perpetuados em perspectiva histórica, quando esbarra na transgressão da norma, não busca desenvolver compreensão, e nos casos mais extremos vemos os números assustadores das execuções violentas. Outro dado preocupante é quanto ao suicídio cometido por essa população, principalmente entre gays que se veem sufocados em seus contextos familiares e sociais.

O relatório do Grupo Gay da Bahia diz que "os gays, em termos absolutos, são o segmento LGBT que mais se suicida, com $60 \%$ de óbitos" (2018, p. 11). Com Rios, Dias e Brazão (2019) compreendemos que na contemporaneidade a expressão do masculino assume uma postura de oposto absoluto quando comparado ao feminino. Neste contexto, ser homem implica porta-se como tal, remetendo-se sempre a virilidade, ao corpo duro, ao andar compenetrado, a fala grossa, para que não se enquadre no mundo avesso do ser mulher, quando a esta atribui-se demasiada fragilidade, em um discurso essencialmente machista e estigmatizado. Com isso, os meninos que não seguem determinada prescrição de como ser, se veem cercados em suas duras realidades, o que em diversos casos, os leva ao suicídio.

Face a esta realidade é que as políticas públicas voltadas para o combate a LGBTfobia deveriam ser fortalecidas ao decorrer dos anos. Mas não é bem isso que se verifica na prática. Em tempos de conservadorismo 
latente (ALMEIDA, 2019) e de cortejo à ditadura militar (NOZAKI, 2019), o que assistimos nos noticiários, nada mais é que censura normatizada dentro dos parâmetros jurídicos. Se fere a Constituição não importa, o importante é a preservação da família e da moral cristã.

Um dos casos de censura a diversidade sexual e explícita demonstração de homofobia, aconteceu na Bienal do Livro do Rio de Janeiro, ocorrida entre os dias 30 de agosto e 08 de setembro de 2019. A polêmica envolvendo o livro de História em Quadrinhos (HQ) da Marvel intitulado "Vingadores - A Cruzada das crianças" provocou diversas manifestações, tanto nas redes sociais quanto na própria bienal12. Uma sutil ilustração de dois jovens super-heróis se beijando no livro, causou profundo incomodo no prefeito do Rio de Janeiro, Marcelo Crivella (Partido Republicano Brasileiro - PRB), que é bispo da Igreja Universal do Reino de Deus.

FIGURA 1 - "Vingadores, a cruzada das crianças" - O beijo censurado

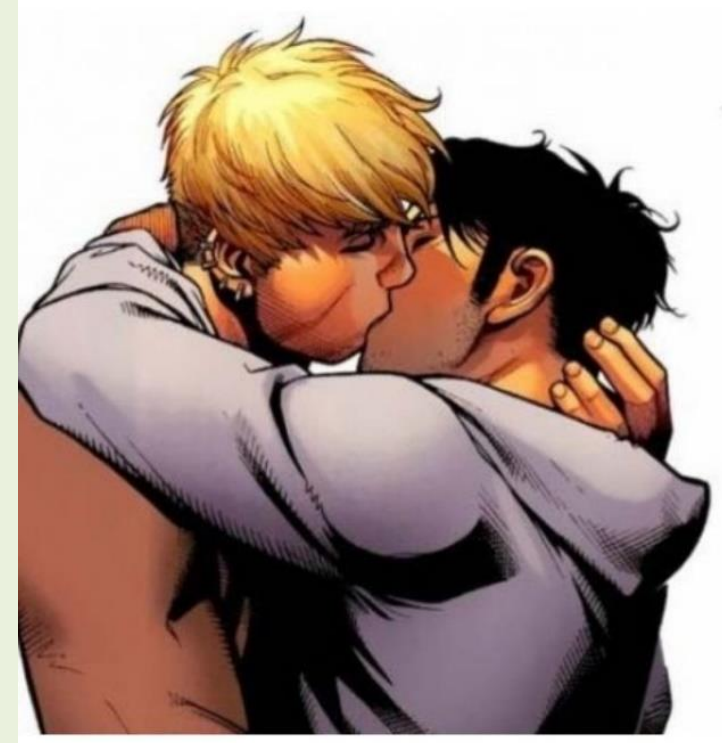

Fonte: www.opovo.com.br.

O descontentamento do prefeito (Leia-se a LGBTfobia) fez com que este solicitasse uma diligência de fiscais da prefeitura no evento para retirar livros considerados "impróprios", livros estes ligados a temática LGBTQI. Determinada ação, nos faz lembrar as atrocidades do DOI-CODI

12 Disponível em: https://www.nsctotal.com.br/noticias/entenda-a-polemica-envolvendopedido-de-recolhimento-de-livro-na-bienal-do-rio-de-janeiro. 
(Destacamento de Operações de Informação - Centro de Operações de Defesa Interna) que promovia "a caça às bruxas" no período da ditadura militar. E isto ocorreu no ano em que o Supremo Tribunal Federal (STF) finalmente criminalizou a LGBTfobia, configurando-a como crime inafiançável e imprescritível assim como os crimes de racismo. A Decisão do órgão máximo de jurisdição, se empreende no contexto da explicita omissão do poder legislativo em discutir a pauta, bem como criar leis que atendam a essa população vulnerável.

Jamais dispostos a promover a tolerância, o respeito, reconhecendo os gêneros e as diversidades sexuais, os integrantes da aliança conservadora agiram junto as instâncias competentes para institucionalizar a censura. Disputando seus interesses em torno do currículo, promoveram a retirada dos descritores gênero e diversidade sexual da BNCC (SEVILLA e SEFFNER, 2017).

Os autores destacam que um dos principais grupos que tencionaram no processo de construção da base, para retirada dos termos foi o Movimento Escola sem Partido. Para Frigotto (2017, p.31) o "Escola sem Partido avança num território que historicamente desembocou na insanidade da intolerância e da eliminação dos seres humanos sob o nazismo, o fascismo e similares. Uma proposta que é absurda e letal pelo que manifesta e pelo que esconde". Trata-se de um Programa que se alimenta da repulsa pelo outro, pelo saudosismo à unívoca perspectiva de escola, família e valores propugnados para estas instituições, meandrado por um teocentrismo autoritário tão característico de tempos e contextos ditatoriais.

Este famigerado movimento criado em 2004, objetiva com intenso empenho combater o que eles chamam de contaminação políticoideológica das escolas de todo Brasil (ALGEBAILE, 2017). De acordo com a autora o movimento utiliza-se de um site $^{13}$ para disseminar suas ideias deslocadas da realidade e fantasiosas, além de incitar denúncias contra docentes, demonizando-os, pois:

${ }_{13}$ Disponível em: https://www.programaescolasempartido.org/. 
[...] mostra uma nítida preocupação com a presença, no processo formativo, de discussões que problematizem as concepções políticas, socioculturais e econômicas hegemônicas, especialmente as relativas às questões de gênero, orientação sexual e modelos familiares, bem como de perspectivas críticas ao capitalismo e à educação conservadora (ALGEBAILE, 2017, p. 67).

Os defensores do Projeto Escola sem Partido advogam contra ao que denominam de "ideologia de gênero". Neste tocante, Penna (2017, p. 45) problematiza "como eles usam esse termo "ideologia de gênero"? Seria uma ideologia antifamília, uma tentativa de transformar os jovens em gays e lésbicas, um ataque à família?". Sevilla e Seffner (2017) avaliam que o fanatismo é tanto, que essa ideologia a qual eles se referem "não existe enquanto corrente teórica e científica". Mas é através das estratégias discursivas fascistas do programa (PENNA, 2017) que se instala o pânico moral (SEVILLA e SEFFNER, 2017).

Em análise do Programa Escola Sem Partido, Assis (2018) aponta três aspectos da insustentabilidade deste. Primeiro, apresenta uma insustentabilidade normativa, quando a argumentação jurídica por parte do programa se utiliza de trechos convenientes, e que confluem aos valores defendidos pelos seus idealizadores. A leitura que é feita da Constituição Federal de 1988 (CF) se mostra avessa à compreensão pretendida quando formulada, ao momento que se contradizem. Um exemplo colocado pela autora é quanto ao princípio constitucional de neutralidade política, ideológica do Estado, que o movimento busca utilizar para atribuir a função pedagógica exercida pelo professor na escola, esta enquanto instituição estatal. A autora vai argumentar que a nossa Constituição se constrói com base no pensamento aristotélico, remetendo-se aos princípios de igualdade e equidade, bem como defende o pluralismo político e ideológico, sendo, portanto, a liberdade de expressão direito constitucionalmente assegurado.

A segunda insustentabilidade diz respeito a natureza teórica do programa, dado que ele não é sem partido como é propagandeado, mas com partido. Uma vez que os pares agrupados em torno do projeto conservador que ancora-se na extrema-direita, agem apresentando nas 
câmaras municipais, assembleias legislativas dos Estados e no próprio Congresso Nacional, projetos de Lei com representação partidária, como é o caso emblemático do ex-senador Magno Malta (PL-ES), ferrenho defensor do projeto da Escola sem Partido naquela casa legislativa. O partidarismo da proposta é evidente, e:

[...] seus objetivos reais versam sobre o enfraquecimento de posicionamentos progressistas, ou "de esquerda" para utilizar uma expressão comum e demasiado generalista, os quais majoritariamente reuniam-se em torno do PT enquanto partido que esteve no poder nos últimos 10 anos, nos provocando a pensar: Escola sem qual partido?

O fato de partidos como o dos Trabalhadores (PT) buscarem no fundamento teórico-epistemológico do marxismo, uma sustentação ideológica, faz com que estes se configurem inimigos, um mal a ser banido do cenário político, bem como das ideias de base marxista que se assuntam nas escolas. De forma nada ingênua, busca-se atacar os professores, sujeitos inquestionavelmente políticos, pela característica básica do papel social e educacional que exercem, quando do fomentar o pensamento crítico e a percepção da realidade por parte dos estudantes.

E por fim, Assis (2018) vai nos dizer da insustentabilidade prática que reside na ausência de "neutralidade normativa e na auto inaplicabilidade" daquilo que prescreve e orienta o Escola sem Partido. Logo, não se sustenta para que seja levado em consideração pelas instâncias deliberativas, estas responsáveis por formular políticas educacionais nos âmbitos municipais, estaduais e nacional.

O Programa Escola sem Partido ao mostrar sua inconstitucionalidade, seu apreço imediato pela anti-intelectualidade, quando não apresenta sólida base teórica, e dada a ambiência democrática mediada pela Constituição Federal de 1988 incompatível com os desígnios nazifascistas propalados por seus correligionários, é peça que precisa ser esvaziada pela militância contrária a este, e claro, balizada pelos princípios constitucionais que asseguram os direitos humanos fundamentais, como o direito à vida. 
O cerceamento da liberdade do professor se constitui na ideologia "sem" partido, ação central que objetiva silenciar inúmeras discussões, que na compreensão que se espera da função social da escola deveriam ali serem suscitadas. Mas vejamos o que pretendem os defensores do projeto, ao quererem fixar cartaz em todas as salas de aulas do Brasil, desde a Educação Infantil ao Ensino Superior, quando argumentam sobre uma contaminação político-ideológica nesses espaçostempos ${ }^{14}$ destinados à construção do processo de ensino aprendizagem.

QUADRO 1: Deveres do professor constantes no cartaz do Programa Escola sem Partido

\section{DEVERES DO PROFESSOR}

\begin{tabular}{c|l}
\hline 1 & $\begin{array}{l}\text { O professor não aproveitará da audiência cativa dos alunos para promover } \\
\text { seus próprios interesses, opiniões, concepções ou preferências ideológicas, } \\
\text { religiosas, morais, políticas e partidárias; }\end{array}$ \\
\hline 2 & $\begin{array}{l}\text { O professor não favorecerá ou prejudicará os alunos em razão de suas } \\
\text { convicções políticas, ideológicas, morais ou religiosas ou da falta delas; }\end{array}$ \\
\hline 3 & $\begin{array}{l}\text { O professor não fará propaganda político-partidária em sala de aula, nem } \\
\text { incitará os seus alunos a participar de manifestações, atos públicos e } \\
\text { passeatas; }\end{array}$ \\
\hline 4 & $\begin{array}{l}\text { Ao tratar de questões políticas, socioculturais e econômicas, o professor } \\
\text { apresentará aos alunos, de forma justa - isto é, com a mesma profundidade e } \\
\text { seriedade -, as principais versões, teorias, opiniões e perspectivas } \\
\text { concorrentes a respeito; }\end{array}$ \\
\hline 5 & $\begin{array}{l}\text { O professor respeitará o direito dos pais a que seus filhos recebam a } \\
\text { educação moral que esteja de acordo com suas próprias convicções; }\end{array}$ \\
\hline 6 & $\begin{array}{l}\text { O professor não permitirá que os direitos assegurados nos itens anteriores } \\
\text { sejam violados pela ação de terceiros dentro da sala de aula. }\end{array}$ \\
\hline
\end{tabular}

Fonte: Elaborado pelos autores com base em informações do site do Movimento Escola sem Partido.

Como é perceptível nos deveres que se encontram no quadro, o grande vilão a ser combatido é o professor. A criminalização do trabalho pedagógico se manifesta quando os apoiadores da proposta:

Além de se manifestarem de forma arrogante, sem nenhuma ética nem respeito com os educadores e a sociedade em geral, emitem uma mensagem de certeza e proposição de ideias supostamente

\footnotetext{
14 A palavra está grafada desta maneira porque faz referência a metodologia de pesquisa no/do/com o cotidiano escolar que aposta na indissociabilidade dos termos.
}

Revista Exitus, Santarém/PA, Vol. 10, p. 01-26, e020065, 2020. 
neutras, mas que escondem, na verdade, um teor fortemente persecutório, repressor e violento (RAMOS, 2017, p. 76).

O intento de calar os professores almeja a formação do alunado acrítico, que não compreende as muitas realidades, dada as nossas diferenças que são de várias ordens, sejam elas de cor, gênero e raça. A mordaça ao impedir que os professores convidem os alunos a participarem de manifestações por exemplo, em outras palavras diz que os alunos precisam ser omissos ou coniventes com as mortes da comunidade LGBT, quando esta continuamente precisa ir as ruas reivindicar o direito à vida digna.

O dever do professor de respeitar a educação moral que os pais dão aos seus filhos com base em suas respectivas convicções, nos leva a questionar, se o professor terá que ser então complacente as comuns manifestações de LGBTfobia no contexto da sala de aula. Uma vez que o aluno pratica determinada religião ou ideologia que vê os corpos e as sexualidades divergentes do padrão heteronormativo, como traidores de gênero, a tolerância precisaria ser dada ao intolerante?

Se com as campanhas de conscientização, que propõem o diálogo, o respeito pelo outro, os números das mortes de LGBTs é tão alto, e lembre-se sempre que as motivações partem em suma do ódio gratuito, ódio que se subterfugia em premissas fundamentalistas que cancelam o outro, negando nossas dissidências, imaginemos na ambiência em que o Escola sem Partido ocorra de forma institucionalizada. Os corpos transgressores da norma se configuram como abjetos de forma ainda mais cruel, uma vez que:

A constituição da figura dos abjetos (e uma certa aproximação com a ideia de não sujeitos) - as vidas tornadas ininteligíveis, desprezíveis, bizarras e/ou estranhas - pode ser compreendida também do ponto de vista dos elementos constitutivos dos processos que materializam discursos (normativos) sobre o gênero e a sexualidade (POCAHY e DORNELLES, 2010, p. 129).

Os corpos que recusam a norma estabelecida, são tornados abjetos porque além de infringir a heteronormatividade, podem ser subversivos no 
tocante ao gênero, negando o binarismo masculino-feminino imposto, e se permitindo estar em um entrelugar denominado movência transgênero 15 (FURLAN e MAIO, 2016). Para as autoras:

A movência transgênero reflete o questionamento às normas, a maleabilidade da construção das identidades e a reflexão acerca dos binarismos, de modo que reconstrua outra perspectiva de sujeito, que não precise se classificar, que possa transitar entre as identidades que the proporcionam bem-estar e que seja aceito e respeitado em suas particularidades (FURLAN e MAIO, 2016, p. 166).

A ousadia de quebrar a amálgama heteronormativa corpo (sexo) gênero-sexualidade (POCAHY e DORNELLES, 2010) perturba os "cidadãos de bem" pois se sentem afrontados. Diante das dissidências que se apresentam para desestabilizar a norma, eles se utilizam de todos os mecanismos, para que essas questões sejam um eterno tabu. E tentam calar essas discussões dentro de uma escola contemporânea, para a qual convergem as diversidades (FURLAN e MAIO, 2016). Isto implica em um processo discriminatório permanente contra os corpos transgressores.

Com base no que acreditam os defensores do modelo único de família empreenderam força tarefa na censura aos termos gênero e diversidade sexual na Base Nacional Comum Curricular (SILVA, BRANCALEONI e OLIVEIRA, 2019). Uma vez que "na construção espacial do sistema escolar, o currículo é o núcleo e o espaço central mais estruturante da função da escola" (ARROYO, 2013, p. 10) se verifica as intensas disputas neste território.

Macedo (2017) argumenta que a inserção do Movimento Escola sem Partido nas discussões relativas à BNCC, se tornou mais efetiva após o processo impeachment que destituiu a presidenta Dilma Rousseff em agosto de 2016. Segundo a autora o referido movimento ocupou a arena de disputa em torno da política curricular, questionando a instância responsável por fomentar a discussão da base e aprovação dela, bem como o conteúdo que se arquitetava nela.

\footnotetext{
15 Termo cunhado por Le Breton (2014) e explorado por Furlan e maio (2016).
} 
No que tange a histórica centralidade do CNE (Conselho Nacional de Educação) enquanto órgão encarregado de discutir através de quadros teoricamente especializados em educação, as políticas educativas de Estado e não de governo, não que o grupo ou grupos que ocupem este último não incidam de forma contundente na formulação de determinadas políticas, O Escola sem Partido advoga no contexto da BNCC pela retirada dessa incumbência da instância colegiada transferindo-a ao Congresso Nacional (MACEDO, 2017).

Percebamos como se movimenta politicamente o reduto conservador, para levar a BNCC a um maior esgarçamento na luta por hegemonia no campo do currículo, considerando que no Congresso Nacional a bancada evangélica nos últimos anos têm contado com expressivo número de parlamentares, o que facilitaria a impetração das ideias propugnadas pelo Escola sem Partido.

O outro ponto que reclamava o movimento dizia respeito aos direitos de aprendizagem que se instituía na BNCC. Conforme os propaladores, a Base deixava de unicamente prescrever conteúdos para orientar a instrução escolarizada, e focava as discussões em temas como raça, gênero, sexualidade, o que na defesa dos mesmos, não se constitui tarefa da escola, pois a educação moral compete unicamente à família, sendo essas questões transgressoras de uma normatividade esperada.

Uma das demandas conservadoras do Escola sem Partido quando tencionaram no processo de construção da Base, foi justamente a questão que eles denominam de ideologia de gênero. Macedo (2017) relata que o movimento agiu no sentido de denunciar essa dita ideologia presente de forma atravessada na proposta do MEC. Segundo a autora, essa e outras:

[...] demandas conservadoras do ESP em relação ao "conteúdo" da BNCC é bastante pontual e aponta menos para o que deve fazer parte do currículo do que para o que deve ser excluído, para que a escola possa "atender a todos". As exclusões citadas explicitamente se referem a demandas político-partidárias, raciais, de gênero e de sexualidade. O potencial dessas exclusões para deslocar as articulações sobre a BNCC é preocupante, na medida em que elas focam diretamente demandas de grupos minoritários - de raça, 
gênero e sexualidade - que, ainda timidamente, têm conquistado algum espaço (MACEDO, 2017, p.517).

A ostensiva ação do movimento resultou no apagamento dos descritores gênero e diversidade sexual na versão final da BNCC apresentada ao final de 2017 para Educação Infantil e para O Ensino Fundamental. De acordo com Junior (2018) a BNCC finalizada sob o comando do governo ilegítimo de Temer, logrou com êxito o que intentava as bancadas religiosas do Congresso Nacional. O autor avalia que:

Sem a presente discussão fica visível a possibilidade de violência de gênero e a discriminação sexual, no âmbito escolar, as quais podem se manifestar por meio de ameaças, agressões físicas, constrangimentos, assédio sexual e/ou moral e abusos sexuais e estupros (JUNIOR, 2018, p. 4).

A negação do outro institucionalizada via política curricular expressa a face conservadora, discursivamente nazista e impetuosa que age por meio de sua forte influência na Educação e sociedade brasileira. A BNCC, anunciada desde a Constituição Federal de 1988 em seu artigo 210, bem como no artigo 26 da Lei de Diretrizes e Bases da Educação Nacional apresenta-se em caráter prescritivo. Conforme Gonçalves (2018, p. 50-51): "pode-se afirmar que a implantação de uma BNCC corresponde a uma política que focaliza o currículo como prescrição, na medida em que "indica" os conhecimentos e as formas de trabalho no cotidiano escolar". Ou seja, silenciar os descritores gênero e diversidade sexual, implica na não discussão destes, pois é um conhecimento valorativo de respeito para com o outro, que não pode ser desenvolvido, uma vez que fere os preceitos cristãos dos conservadores.

No tocante a esses temas promover o esvaziamento da discussão na escola significa não conceder espaço para o diferente; é como se o Estado Democrático de Direito estivesse para que alguns exerçam os seus direitos, e outros não. A ação da aliança conservadora de modo específico, os fundamentalistas religiosos que a todo custo buscam hegemonia absoluta 
sob grupos historicamente marginalizados, expressa o quanto é necessário resistirmos cotidianamente.

Quando nos propomos a discutir sobre o apagamento dos descritores ausentes na Base, estamos a corroborar com Rios, Dias e Brazão (2019, p. 777) quando afirmam que:

Para estudantes e/ou profissionais gays, a escola se apresenta num misto entre o possível espaço de construção da liberdade sexual ao tempo em que também se coloca enquanto espaço que fabrica e dissemina preconceitos.

E levamo-nos ao questionamento, sobre qual escola queremos e defendemos. A questão aqui é de fato sobre nós e eles, é sobre constituirmonos como corpos de resistência, em tempos de avanço aparente da anti democracia, representado por um governo que apresenta como bandeiras a Família, Deus acima de Todos, armamento dos raivosos cidadãos de bem, ser LGBT significa sobreviver, resistir.

Pois diante desta realidade marcada pelo ódio fascista, que é cego e incapaz de ver o outro (TIBURI, 2016) essa população vai sendo negada, condenada a própria sorte. E como podemos proceder se não pela resistência? A história do movimento LGBT foi construída pela luta, por aqueles que se organizavam e reivindicavam o direito de viver (SIMÕES e FACCHINI, 2009). Muitos estigmas rotuladores foram sendo descontruídos, mas outros se perpetuam no tempo e na história, o que nos solicita resistência.

\section{CONSIDERAÇÕES FINAIS}

Nos limites deste texto buscamos expressar em um caminho teóricoreflexivo a ansiedade a nós causada pela LGBTfobia. O silenciamento dos descritores gênero e diversidade sexual na BNCC mais que nos tornam abjetos, contribui para estatística apresentada anualmente pelo Grupo Gay da Bahia, que é sobre quantos de nós vai morrendo, o motivo? Ódio! Ódio como política, ódio alimentado pela negação de vidas que são invisibilizadas cotidianamente. Quando deveríamos estar avançando na 
discussão desta pauta, com uma política curricular compromissada com a não discriminação, valorizando a nossa pluralidade, o que se vê é o governo Bolsonaro se omitindo das questões LGBTQIA+ frente a ONU (Organização das Nações Unidas).

Compromissado com sua base político-ideológica o governo lançou como política pública o "passaporte para a década de 1930" quando na Era Vargas se instituiu a Educação Moral e Cívica. O PECIM (Programa Nacional de Escolas Cívico-militares) pretende implementar 216 escolas em todas as unidades federativas até 2023. De acordo com informações do portal do Ministério da Educação (MEC) 16, "O presidente Jair Bolsonaro destacou a disciplina em escolas com tutela de militares e as classificou como fundamentais para o desenvolvimento do país". Gênero e diversidade sexual serão temas erradicados dentro deste modelo.

Mesmo nestes dias sombrios precisamos ser resistência. Nossos corpos precisam ser usados como estratégia política. A militância precisa estar imersa em nossa escrita, em nossa forma de se colocar nos espaços, mesmo que muitas vezes camuflada, em razão do medo, porque fora assim nos anos de chumbo. Que não precisemos ser LGBTs heteronormativos para se adequar na caixinha deles, no preto e branco apático. O arco-íris é colorido, e representa a nossa diversidade.

E se aproximando do ponto final, é importante dizer que acreditemos em nós, que acreditemos em nossa luta, na certeza de que não somos os abjetos tornados por eles. As identidades transgressoras desenhadas em nossos corpos sexuados, tem que (re)existir, pois aí reside nossa riqueza humana. Até o momento de fechamento deste texto o famigerado cartaz do Programa Escola sem Partido ainda não é uma realidade, porque ainda sim, temos muitas vozes que nas instâncias decisórias falam por nós. E é nesta linha que devemos proceder, militantes em nossos locais de ação, enquanto alunos, professores, formadores e principalmente vidas LGBT. Jamais

16 http://portal.mec.gov.br/component/content/article?id=79931 
compreendendo que essa é uma luta só nossa, mas que deve ser liderada por nós.

É importante que se deixe acessa a chama da esperança de dias melhores. Pois, como diz a letra da música Flutua de Jhonny Hooker (2017): "Um novo tempo há de vencer, pra que a gente possa florescer, e baby amar, sem temer".

\section{REFERÊNCIAS}

ALGEBAILE, E. Escola sem Partido: o que é, como age, para que serve. In: FRIGOTTO, G. (Org.). Escola "sem" partido: Esfinge que ameaça a educação e a sociedade brasileira. Rio de Janeiro: UERJ/LPP, 2017, p. 63-74, 2017.

ALMEIDA, R. de. Bolsonaro presidente: conservadorismo, evangelismo e a crise brasileira. Revista Novos Estudos, v. 38, n.1, 2019.

APPLE, M. Endireitar" a educação: as escolas e a nova aliança conservadora. Currículo sem fronteiras, v. 2, n. 1, p. 55-78, 2002.

ARROYO, M. G. Currículo, território em disputa. Editora Vozes Limitada, 2013.

ASSIS, A. E. S. Q. Escola sem partido: projeto sem sustância. Revista Exitus, v. 8, n. 2, p. 15-33, 2018. Disponível em:

<http://www.ufopa.edu.br/portaldeperiodicos/index.php/revistaexitus/article /view/527> Acesso em: 02 de fevereiro de 2020.

BULGARELLI, L. Moralidades, direitas e direitos LGBTI nos anos 2010. In:

GALLEGO, E. S. (Org.). O ódio como política: a reinvenção das direitas no Brasil. Boitempo Editorial. 2018.

FRIGOTO, G. A gênese das teses do Escola sem Partido: esfinge e ovo da serpente que ameaçam a sociedade e a educação. In: FRIGOTO, G. (Org.). Escola "sem" partido: Esfinge que ameaça a educação e a sociedade brasileira. Rio de Janeiro: UERJ/LPP, 2017, p. 63-74, 2017.

FURLAN, C. C.; MAIO, E. R. Pedagogias do corpo: é possível a escola ser um espaço de reconstrução? In: MESSEDER, S.; CASTRO, M. G. e MOUTINHO, L. (Org.). Enlaçando Sexualidades: uma tessitura interdisciplinar no reino das sexualidades e das relações de gênero. Salvador: Edufba, 2016.

GONÇALVES, R. M. Bricolagens praticadas e políticaspráticas de currículos nos cotidianos escolares. $132 \mathrm{f}$. Tese (Doutorado em Educação) Universidade do Estado do Rio de Janeiro, Rio de Janeiro, 2018. 
GONÇALVES, R. M. Autonomia e Políticas práticas de Currículos: uma equação entre raízes e opções. Educ. Real., Porto Alegre, v. 44, n. 3, e84870, 2019. Disponível em:

<http://www.scielo.br/scielo.php?script=sci_arttext\&pid=\$217562362019000300401 \&lng=en\&nrm=iso>. Acesso em: 26 de maio de 2020. Epub Sep 12, 2019. https://doi.org/10.1590/2175-623684870.

GONÇALVES, R. M. et at. A BNCC na contramão das demandas sociais: planejamento com e planejamento para. Práxis Educacional, [S.I.], v. 16, n. 38, p. 338-351, jan. 2020. ISSN 2178-2679. Disponível em:

<http://periodicos2.uesb.br/index.php/praxis/article/view/6012>. Acesso em: 26 de maio de 2020. doi: https://doi.org/10.22481/praxisedu.v16i38.6012.

GONÇALVES, R. M. Conversas sobre práticas e currículos entre professoras: artesania e maneiras de fazer o cotidiano escolar. Linguagens, Educação e Sociedade, Teresina, Ano 23, Edição Especial, dez. 2018. Disponível em: https://revistas.ufpi.br/index.php/lingedusoc/article/view/7876. Acesso em 26 de maio de 2020. Doi: https://doi.org/10.26694/les.v1i1.7876

GONZALEZ, L. Racismo e sexismo na cultura brasileira. Revista Ciências Sociais Hoje, v. 2, n. 1, 1984, p. 223-244.

GREEN, J. N.; POLITO, R. Frescos trópicos: fontes sobre a homossexualidade masculina no Brasil, 1870-1980. Editora José Olympio, 2004.

GRUPO GAY DA BAHIA. População LGBT morta no Brasil - Relatório 2018 GGB.

JUNIOR, P.R.S. A questão de gênero, sexualidade e orientação sexual na atual Base Nacional Comum Curricular (BNCC) e o movimento

LGBTTQIS. Revista de Gênero, Sexualidade e Direito, v. 4, n. 1, p. 1-21 , 2018.

LEÃO, A. M. de C.; RIBEIRO, P. R. M. As políticas educacionais do Brasil: a (in) visibilidade da sexualidade e das relações de gênero. Revista Ibero-

Americana de Estudos em Educação, v. 7, n. 1, p. 28-37, 2012.

LIMA, T. S. Ensaio de cartografia política: as Eleições de 2018. Terra Livre, v. 1, n. 52, p. 658-695, 2019.

MACEDO, E. As demandas conservadoras do movimento escola sem partido e a base nacional curricular comum. Educação \& Sociedade, v. 38, n. 139, p. 507-524, 2017.

NOZAKI, W. Um capitão entre generais: a presença dos militares no governo Bolsonaro. In: AZEVEDO, J. S. G. de; POCHMANN, M. (Org.). Brasil: Incertezas e submissão? São Paulo: Fundação Perseu Abramo, p. 83-104, 2019. 
PENNA, F. A. O Escola sem Partido como chave de leitura do fenômeno educacional. In: FRIGOTTO, G. (Org.). Escola "sem" partido: Esfinge que ameaça a educação e a sociedade brasileira. Rio de Janeiro: UERJ/LPP, p. 35-48, 2017.

POCAHY, F.; DORNELLES, P. G. Um corpo entre o gênero e a sexualidade: notas sobre educação e abjeção. Instrumento, Juiz de Fora, v. 1, n. 1, p. 125135, 2010.

RAMOS, M. N. Escola sem Partido: a criminalização do trabalho pedagógico. In: FRIGOTTO, G. (Org.). Escola "sem" partido: Esfinge que ameaça a educação e a sociedade brasileira. Rio de Janeiro: UERJ/LPP, p. 75-85, 2017.

RIOS, P. P. S.; DIAS, A. B.; BRAZÃO, J. P.G. "Lembro-me de querer andar durinho, como se diz que homem deve ser": a construção do corpo gay na escola. Revista Exitus, v. 9, n. 4, p. 775-804, 2019. Disponível em: < http://www.ufopa.edu.br/portaldeperiodicos/index.php/revistaexitus/article/ view/1033> Acesso em: 12 de janeiro de 2020.

ROCHA, K. A. Diversidade sexual e combate à homofobia no cenário das políticas públicas para a educação. In: Congresso Nacional de Educação, I Seminário Internacional de Representações Sociais, Subjetividade e Educação, 10, 2011, Curitiba. Anais [...] Curitiba: PUC - PR, 2011. Disponível em: http://educere.bruc.com.br/CD2011/pdf/5958_2939.pdf. Acesso em: 20 de ago. 2019.

SEVILLA, G.; SEFFNER, F. A guinada conservadora na educação: reflexões sobre o novo contexto político e suas reverberações para a abordagem de gênero e sexualidade na escola. In: Seminário Internacional fazendo Gênero, 11 \& Women's Worlds Congress, 13, 2017, Florianópolis. Anais [...] Florianópolis: UFSC, 2017.Disponível em:http://www.en.wwc2017.eventos.dype.com.br/resources/anais/14994650 18_ARQUIVO_textocompletofazendogeneroversaofinalgabrielasevillaefernan doseffner.pdf. Acesso em: 08 de ago. 2019.

SILVA, C.S.F.; BRANCALEONI, A. P. L.; OLIVEIRA, R.R. Base Nacional Comum Curricular e diversidade sexual e de gênero: (des)caracterizações. Revista Ibero-Americana de Estudos em Educação, Araraquara, v. 14, n. esp. 2, p. 1538-1555, jul. 2019.

SILVEIRA, S. A. Concentração, modulação e desinformação nas redes. In: AZEVEDO, J. S. G. de. POCHMANN, M. (Org.). Brasil: Incertezas e submissão? São Paulo: Fundação Perseu Abramo, p. 27-44, 2019.

SIMÕES, J. A.; FACCHINI, R. Na trilha do arco-íris: do movimento homossexual ao LGBT. Editora Fundação Perseu Abramo, 2009. 
SOUZA, J. A Classe Média no espelho: sua história, seus sonhos e ilusões, sua realidade. Rio de Janeiro: Estação Brasil, 2018.

TIBURI, M. Como conversar com um fascista. $7^{\circ} \mathrm{ed}$. Rio de Janeiro: Editora Record, 2015.

VALIM, P.; FERNANDES, F. B. M. "Quanto mais purpurina melhor": questões de gênero e sexualidade no Brasil do governo Bolsonaro. In: AZEVEDO, J. S. G. de. POCHMANN, M. (Org.). Brasil: Incertezas e submissão? São Paulo: Fundação Perseu Abramo, p. 401-420. 2019.

Recebido em: 17 de março de 2020 Aprovado em: 01 de junho de 2020 Publicado em: 17 de agosto de 2020 (c) (1) (8) 